RESEARCH ARTICLE

\title{
Single-frequency and free-running operation of a single-pass pulsed Ho:YLF amplifier
}

\author{
Yunpeng Wang, Youlun Ju, Tongyu Dai, Dong Yan, and Baoquan Yao \\ National Key Laboratory of Tunable Laser Technology, Harbin Institute of Technology, Harbin 150001, China \\ (Received 7 July 2020; revised 7 August 2020; accepted 12 August 2020)
}

\begin{abstract}
A single-frequency pulsed holmium-doped yttrium lithium fluoride (Ho:YLF) amplifier pumped by a Tm-doped fiber laser was demonstrated. The seed was an injection-seeded $Q$-switched Ho:YLF laser. The output energy from the singlefrequency pulsed amplifier was $24.2 \mathrm{~mJ}$, with a pulse width of $250 \mathrm{~ns}$ at a pulse repetition frequency (PRF) of $100 \mathrm{~Hz}$. The energy stability during $30 \mathrm{~min}$ was improved to $1 \%$ after the single-frequency pulsed Ho:YLF laser was amplified. The line width of the single-frequency pulsed spectrum of the Ho:YLF amplifier was $2.81 \mathrm{MHz}$. The single-frequency pulsed Ho:YLF amplifier can be applied to differential absorption lidar (DIAL), since its output spectrum is around the $\mathrm{P} 12 \mathrm{CO}_{2}$ absorption line.
\end{abstract}

Keywords: differential absorption lidar; $\mathrm{Ho}$ :YLF amplifier; $\mathrm{P} 12 \mathrm{CO}_{2}$ absorption line; single frequency

\section{Introduction}

Narrow-line-width pulsed solid-state lasers in the $2 \mu \mathrm{m}$ eyesafe spectral region are usually used as the lidar emitter in coherent Doppler lidars for wind field measurement or in differential absorption lidars (DIALs) for monitoring the concentrations of gases such as $\mathrm{CO}_{2}$ and $\mathrm{H}_{2} \mathrm{O}^{[1-4]}$. A lidar configuration requires an emitter with high energy to increase the detection range, a long pulse width to improve the spectrum resolution and a narrow line width to enhance the spectral purity ${ }^{[5]}$. A critical technique for obtaining a narrow-line-width pulsed laser is the injection of a singlefrequency continuous-wave (CW) laser into a $Q$-switched slave laser ${ }^{[6,7]}$. In addition, there are two ways to obtain a long pulse width: one is to increase the cavity length of the $Q$-switched slave laser; and the other is to ensure that the slave laser operates at a lower energy. Increasing the cavity length, however, leads to difficulties with the cavity design, a complex structure and a large laser volume. Compared with a longer resonator, it is an effective approach for realizing a pulsed laser with narrow line width, long pulse width and high energy, by making the $Q$-switched slave laser operate at

Correspondence to: T. Dai, National Key Laboratory of Tunable Laser Technology, Harbin Institute of Technology, Harbin 150001, China. Email: daitonhyu2006@126.com a lower energy and then increasing the output energy through an amplifier system.

A Ho-doped single-frequency solid-state laser is a significant means for obtaining a $2 \mu \mathrm{m}$ narrow-line-width laser that benefits from an insensitivity to temperature, low quantum defects and low upconversion $\operatorname{losses}^{[8,9]}$. Anisotropic holmium-doped yttrium lithium fluoride (Ho:YLF) crystals have the capability to generate high energy lasers due to the combination of a high emission cross-section and a long upper-level lifetime $(14 \mathrm{~ms})$ for $\mathrm{Ho}^{3+}$ transition ${ }^{[10,11]}$. More importantly, the output spectrum of a Ho:YLF laser can be tuned over many $\mathrm{CO}_{2}$ characteristic absorption lines ${ }^{[12-14]}$. The most commonly used $\mathrm{CO}_{2}$ absorption line around the $2050 \mathrm{~nm}$ emission peak of Ho:YLF crystal is $2050.967 \mathrm{~nm}$. In 2009, Bai et al. proposed a single-frequency injection-seeded $Q$-switched Ho:YLF laser for $\mathrm{CO}_{2}$ measurement ${ }^{[15]}$. With a pulse repetition frequency (PRF) of $1.25 \mathrm{kHz}$, the output energy and pulse width of a single-frequency Ho:YLF laser were $5.5 \mathrm{~mJ}$ and $50 \mathrm{~ns}$, respectively. The online wavelength was locked to the R30 $\mathrm{CO}_{2}$ absorption line at $2050.967 \mathrm{~nm}$, and the offline wavelength was $2051.023 \mathrm{~nm}$. In 2014, Gibert et al. reported a single-frequency two-wavelength pulsed Ho:YLF laser for $\mathrm{CO}_{2}$ DIAL applications ${ }^{[16]}$. At a PRF of $2 \mathrm{kHz}$, a maximum single-frequency output energy of $13.5 \mathrm{~mJ}$ was obtained, with a pulse width of $42 \mathrm{~ns}$. The online wavelength was locked to the $\mathrm{R} 30 \mathrm{CO}_{2}$ absorption line at $2050.967 \mathrm{~nm}$. 
Near the $2064 \mathrm{~nm}$ emission peak of Ho:YLF crystal $(\pi-$ or $\sigma$-polarization), however, the $\mathrm{P} 12 \mathrm{CO}_{2}$ absorption line at $2064.414 \mathrm{~nm}$ was another choice because it has higher absorption intensity, and there is no absorption of other trace gases. Therefore, the single-frequency pulsed laser around $2064 \mathrm{~nm}$ based on Ho:YLF crystal is an extremely promising emitter for DIAL systems.

In this paper we propose a single-frequency single-pass Ho:YLF amplifier around the $\mathrm{P} 12 \mathrm{CO}_{2}$ absorption line. The output characteristics of the Ho:YLF amplifier under freerunning and single-frequency operation were compared for the first time. An output energy of $24.2 \mathrm{~mJ}$ with a pulse width of $250 \mathrm{~ns}$ at a PRF of $100 \mathrm{~Hz}$ was obtained. The energy stability during $30 \mathrm{~min}$ was improved from $3.8 \%$ to $1 \%$ when the single-frequency pulsed Ho:YLF laser was amplified. The pulse build-up time of the Ho:YLF amplifier under single-frequency operation was $0.37 \mu$ s shorter than that of free-running operation. The line width of the singlefrequency pulsed Ho:YLF amplifier measured by a heterodyne technique was $2.81 \mathrm{MHz}$.

\section{Experiment}

The experimental setup of the single-frequency $Q$-switched Ho:YLF ring laser and the single-pass amplifier is shown in Figure 1. The $Q$-switched Ho:YLF ring laser comprising five mirrors was pumped by a $25 \mathrm{~W}$ Tm-doped all-fiber laser, and injected with a single-frequency CW Ho:YLF laser at the P12 $\mathrm{CO}_{2}$ absorption line of $2064.414 \mathrm{~nm}$. To achieve a long pulse-width output, the total physical length of the ring laser was $2.53 \mathrm{~m}$. The length-to-width ratio of the ring laser was $6: 1$, which indicated that the ring laser had a relatively small volume. See Wu et al. ${ }^{[17]}$ and Wang et al. ${ }^{[18]}$ for more details about the single-frequency CW Ho:YLF laser and the pulsed Ho:YLF ring laser. Two laser output directions were obtained when the Ho:YLF ring laser was under freerunning operation. In contrast, the ring laser realized unidirectional operation to achieve single-frequency pulsed laser output when it was injected by the single-frequency $\mathrm{CW}$ Ho:YLF laser. For convenience, both the single-frequency CW Ho:YLF laser and the ring laser are considered as the seed laser.

The single-pass amplifier with three adjacent Ho:YLF crystals was end-pumped by an ellipse-polarization Tmdoped fiber laser with a central wavelength of $1940 \mathrm{~nm}$. At a total pump power of $33.9 \mathrm{~W}$, the powers of $p$-polarized and $s$-polarized light were $17.6 \mathrm{~W}$ and $16.3 \mathrm{~W}$, respectively. The pump beam was focused by the spherical positive lens f3 with a focal length of $200 \mathrm{~mm}$. The waist radii of the pump beam in the front face of the first Ho:YLF crystal were $0.34 \mathrm{~mm}$ in the horizontal position and $0.44 \mathrm{~mm}$ in the vertical position. The single-frequency pulsed Ho:YLF seed laser beam was focused by the spherical positive lens f2 with a focal length of $240 \mathrm{~mm}$, and the waist radius was $0.48 \mathrm{~mm}$ in the center of the first Ho:YLF crystal. M6 was a coated plane mirror, with high reflectivity from $1.94 \mu \mathrm{m}$ to $2.06 \mu \mathrm{m}$. P2 and P3 were $45^{\circ}$ polarizers with high reflectivity at $1.9 \mu \mathrm{m}$, high transmission for $2.06 \mu \mathrm{m} p$-polarized light and high reflectivity for $2.06 \mu \mathrm{m}$ $s$-polarized light. Three $a$-cut Ho:YLF crystals with the dimensions $5 \mathrm{~mm} \times 4 \mathrm{~mm} \times 60 \mathrm{~mm}, 5 \mathrm{~mm} \times 4 \mathrm{~mm} \times 30 \mathrm{~mm}$ and $4 \mathrm{~mm} \times 5 \mathrm{~mm} \times 40 \mathrm{~mm}$ were doped with 0.5 at. $\% \mathrm{Ho}^{3+}$, wrapped with indium foil, and mounted on a copper heat sink. Both end faces of the three crystals were coated with $1.9 \mu \mathrm{m}$ and $2.1 \mu \mathrm{m}$ antireflection (AR) coating. The temperature of the three Ho:YLF crystals was controlled at $18 \pm 0.1^{\circ} \mathrm{C}$ by circulating water. The first two Ho:YLF crystals were oriented with their $c$-axes horizontal and the last Ho:YLF crystal was oriented with its $c$-axis vertical, so

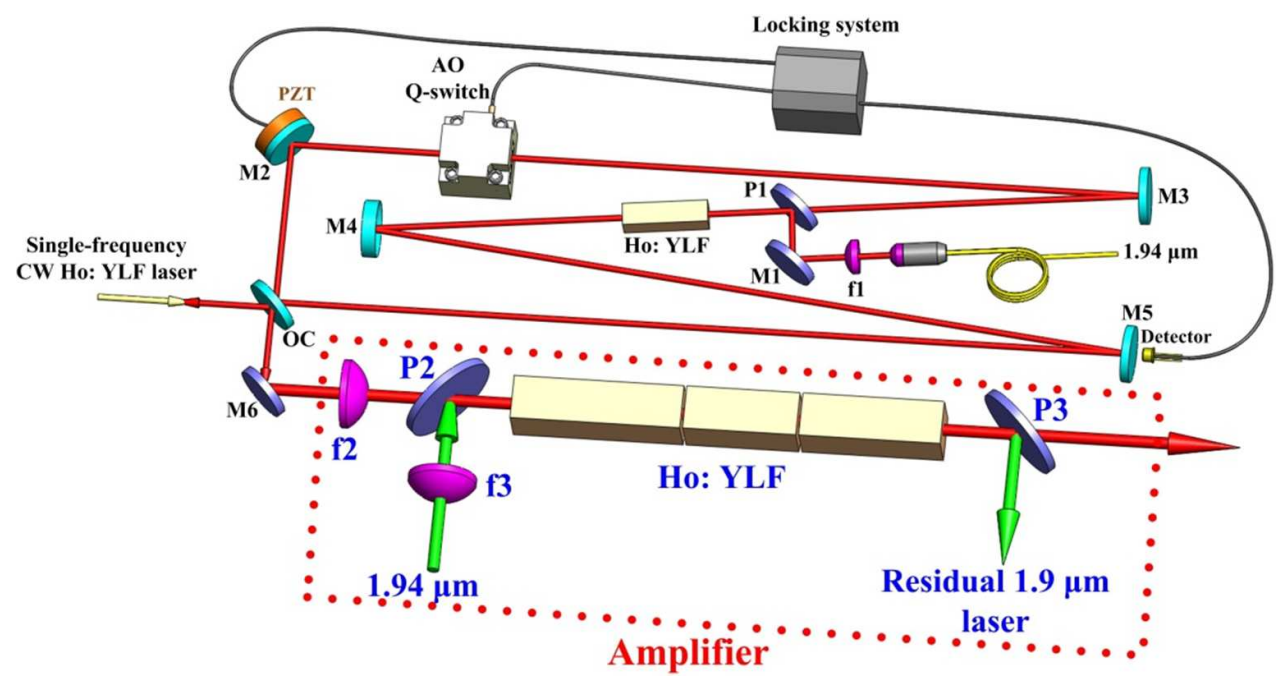

Figure 1. Experimental setup of the single-frequency pulsed Ho:YLF ring laser and the single-pass amplifier. 

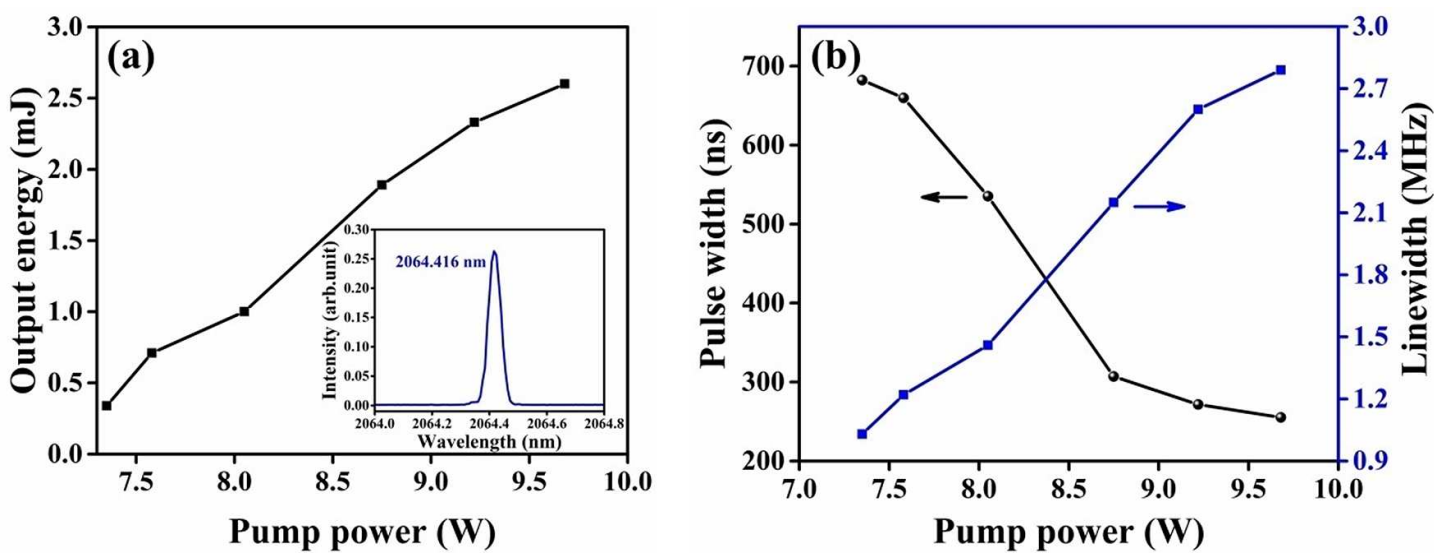

Figure 2. Output characters of the single-frequency pulsed Ho:YLF seed laser. (a) Output energy versus pump power; (b) pulse width and line width versus pump power.

that the $p$-polarized pump laser through the first two crystals and the $s$-polarized pump laser through the last crystal had a low loss due to the polarization absorption characteristics of the Ho:YLF crystal. Under a pump power of $33.9 \mathrm{~W}$, the absorption efficiencies of $p$-polarized and $s$-polarized pump light through the first Ho:YLF crystal were 53\% and $27 \%$, respectively. To further increase the absorption efficiency of $p$-polarized light, the second Ho:YLF crystal was used. The corresponding absorption efficiencies of $p$-polarized and $s$-polarized pump light were $70.1 \%$ and $41.7 \%$, respectively. In order to increase the absorption efficiency of $s$-polarized light, the last Ho:YLF crystal was employed. The corresponding absorption efficiencies of $p$-polarized and $s$-polarized pump light were $75.7 \%$ and $72.8 \%$, respectively, resulting in a total absorption efficiency of $74.3 \%$.

\section{Results and discussion}

The output energy of the single-frequency pulsed Ho:YLF seed laser at a PRF of $100 \mathrm{~Hz}$ measured by an energy meter (Coherent, J-10MB-HE) is illustrated in Figure 2(a). Under a pump power of $9.68 \mathrm{~W}$, an output energy of $2.6 \mathrm{~mJ}$ was obtained. The wavelength from the pulsed output spectrum monitored by an optical spectrum analyzer (Yokogawa, AQ6375B) was centered at $2064.416 \mathrm{~nm}$, which was around the $\mathrm{P} 12 \mathrm{CO}_{2}$ absorption line, as shown in the inset in Figure 2(a). The pulse width of the single-frequency pulsed Ho:YLF seed laser recorded by an InGaAs detector and line width measured by a heterodyne technique as functions of the seed pump power are shown in Figure 2(b). A pulse width of $255.2 \mathrm{~ns}$ and a line width of $2.79 \mathrm{MHz}$ were achieved at a seed pump power of $9.68 \mathrm{~W}$.

The output energy of the single-frequency single-pass pulsed Ho:YLF amplifier at different seed energies is shown in Figure 3. It can be seen that the output energy increases with pump power under the same seed energy. At the incident pump power of $33.9 \mathrm{~W}$ and a seed energy of $2.6 \mathrm{~mJ}$, the output energy of the single-frequency Ho:YLF amplifier

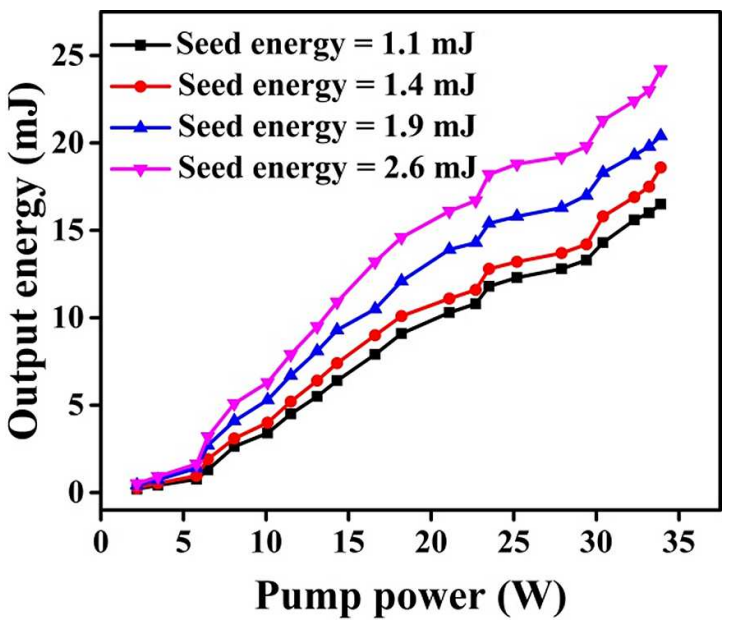

Figure 3. Output energy of the single-frequency Ho:YLF amplifier versus pump power.

reached $24.2 \mathrm{~mJ}$, with a pulse width of $250 \mathrm{~ns}$ at a PRF at $100 \mathrm{~Hz}$, resulting in a gain of $9.69 \mathrm{~dB}$. The pulse width was narrower after amplification because the population inversion was consumed at the pulse leading edge, and a smaller gain was obtained at the pulse trailing edge.

The energy fluctuations of the pulsed Ho:YLF amplifier under free-running and single-frequency operation were investigated, as shown in Figure 4. Under free-running operation, the standard deviation of the amplifier energy during $30 \mathrm{~min}$ was $0.37 \mathrm{~mJ}$, corresponding to an energy stability of $3.8 \%$, which was calculated by dividing the standard deviation by the mean. When the single-frequency seed laser was amplified, the standard deviation of the amplifier energy during $30 \mathrm{~min}$ was $0.21 \mathrm{~mJ}$, corresponding to an energy stability of $1 \%$. The energy stability was improved after the single-frequency seed laser was amplified because the gain competition effect from two directions of the Ho:YLF ring laser was eliminated by the injection of the single-frequency CW Ho:YLF laser. The amplifier output energy under freerunning operation was approximately half that of singlefrequency operation due to the bidirectional output of the ring laser. 


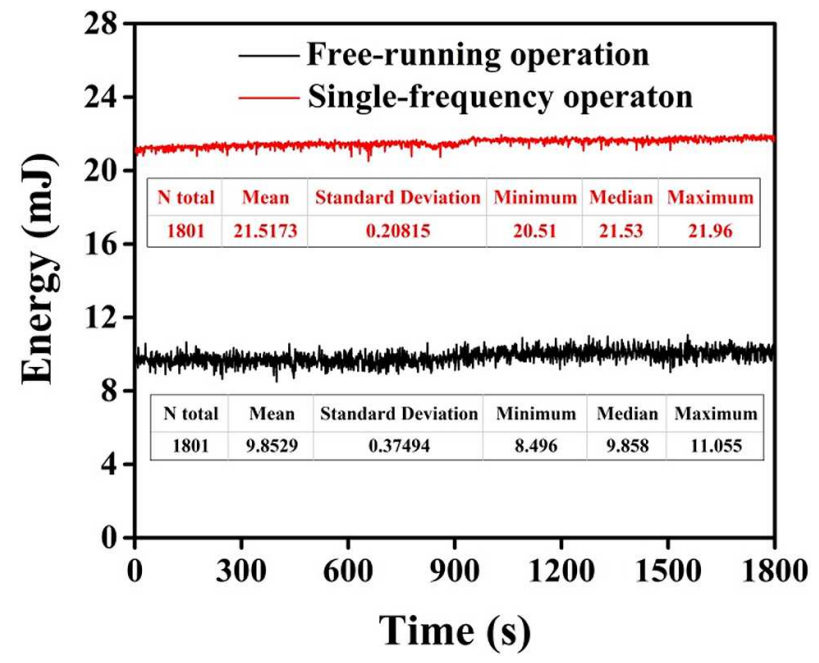

Figure 4. Energy stability of the Ho:YLF amplifier under free-running and single-frequency operation.

The pulse build-up time of the Ho:YLF amplifier under free-running and single-frequency operation is shown in Figure 5. At a PRF of $100 \mathrm{~Hz}$ and a pump power for the Ho:YLF seed laser of $9.68 \mathrm{~W}$, the pulse build-up time of the Ho:YLF amplifier was $2.58 \mu$ s under free-running operation, and $2.21 \mu \mathrm{s}$ under single-frequency operation. The phenomenon of a shorter pulse build-up time under single-frequency operation was mainly caused by the upper level population of $\mathrm{Ho}^{3+}$ being excited by the singlefrequency $\mathrm{CW}$ Ho:YLF laser injection; the stimulated radiation then became dominant. Therefore, pulse establishment was completed ahead of time compared to the spontaneous radiation of the pulsed Ho:YLF laser under free-running operation.

The temporal pulse shapes of the Ho:YLF amplifier were measured with a high-speed InGaAs detector $(1 \mathrm{GHz}$ bandwidth) connected to a digital oscilloscope $(1 \mathrm{GHz}$ bandwidth) at a PRF of $100 \mathrm{~Hz}$; and the fast Fourier transform (FFT) curves of the temporal shapes were calculated, as shown in Figure 6. The emergence of mode beating under free-running operation as shown in Figure 6(a) was due to the multi-longitudinal-mode operation of the ring laser. The free spectrum range (FSR) of $116 \mathrm{MHz}$ was obtained from the FFT curve, which was in correspondence to the $2.53 \mathrm{~m}$ ring laser. Compared with Figure 6(a), the temporal pulse shape of the Ho:YLF amplifier at $24.2 \mathrm{~mJ}$ in Figure 6(b) was relatively smooth, and there were no mode beating spikes from the FFT curve due to the single-frequency operation of the ring laser.

The pulsed spectrum of the Ho:YLF amplifier under single-frequency operation was measured by a heterodyne technique. The frequency of the $\mathrm{CW}$ single-frequency
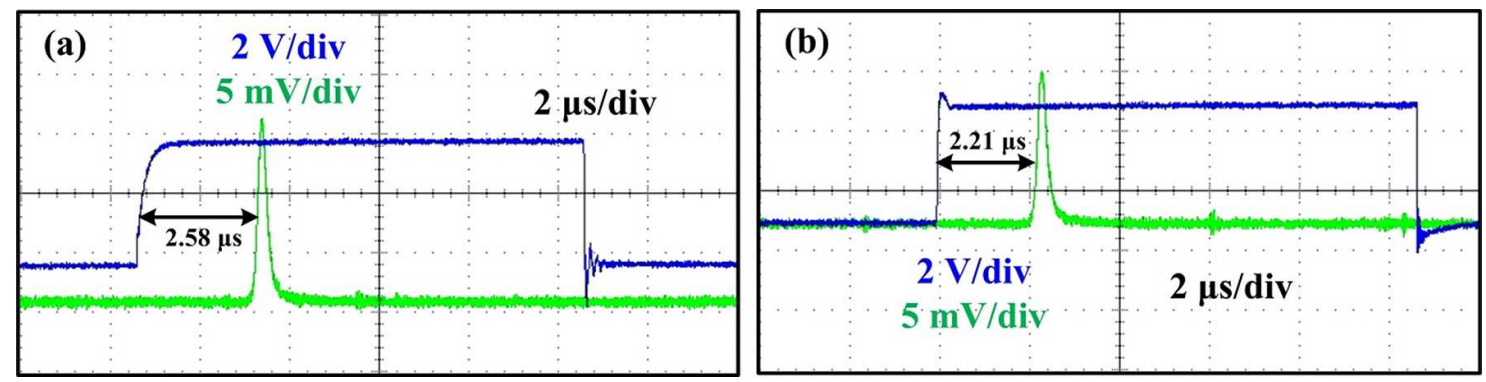

Figure 5. Pulse build-up time of the Ho:YLF amplifier. (a) Under free-running operation; (b) under single-frequency operation.
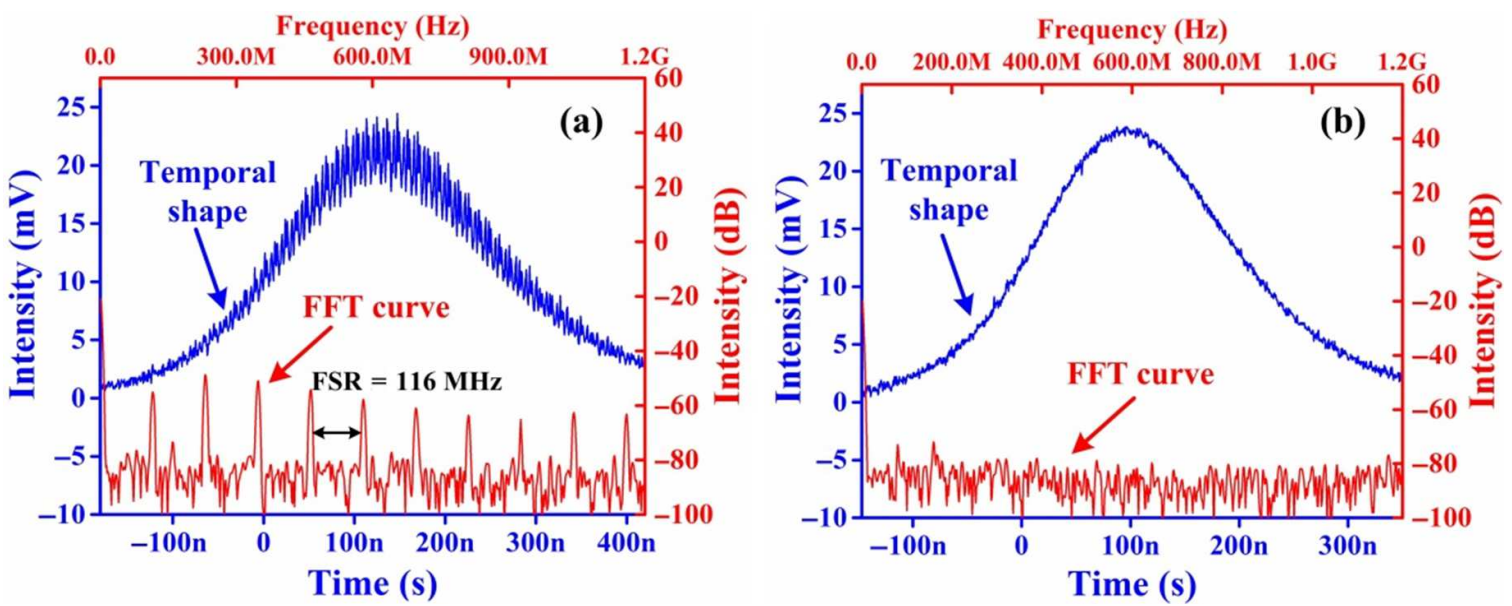

Figure 6. Temporal shapes and FFT curves for the Ho:YLF amplifier. (a) Free-running operation; (b) single-frequency operation. 

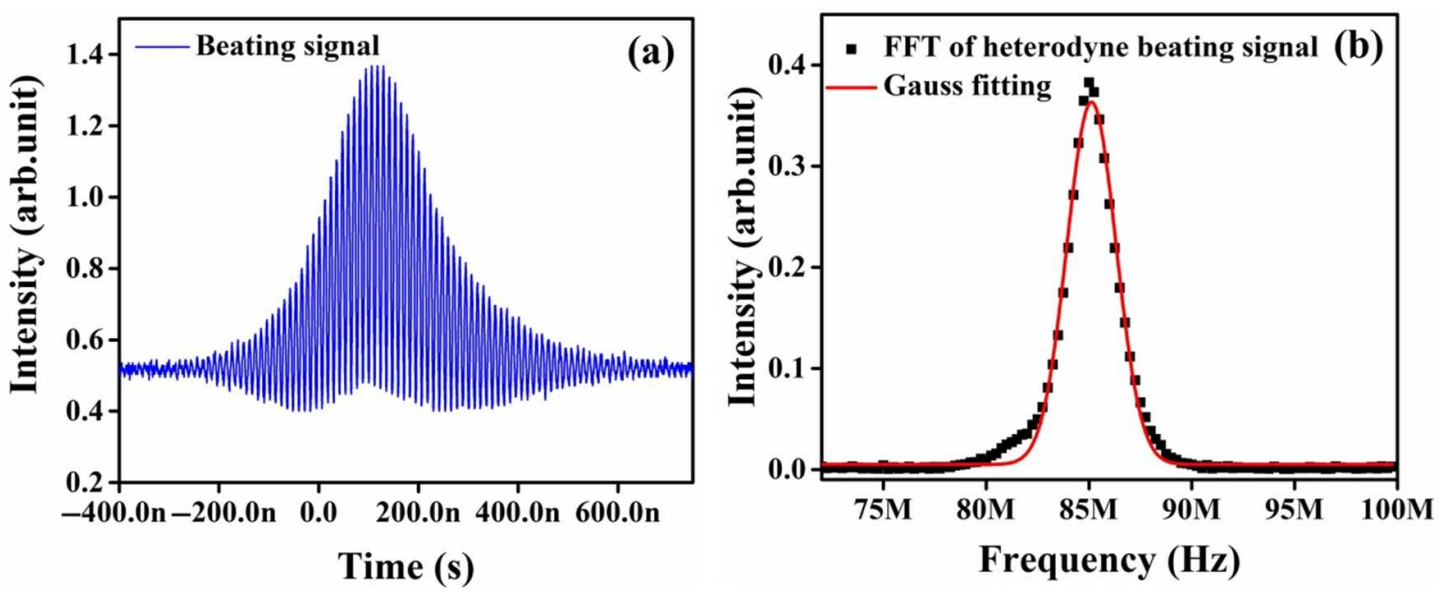

Figure 7. Laser properties of the single-frequency Ho:YLF amplifier. (a) Beating signals; (b) fast Fourier transform (FFT) spectrum of the beating signals.

Ho:YLF laser was shifted by an $80 \mathrm{MHz}$ acousto-optic modulator (AOM). The frequency-shifted CW Ho:YLF laser and a small part of the single-frequency pulsed Ho:YLF laser from the amplifier were then mixed into a fiber combiner for measuring the beating signal. The beating signal recorded by an InGaAs detector and a digital oscilloscope is shown in Figure 7(a). The line width of $2.81 \mathrm{MHz}$ was estimated from the pulsed spectrum after an FFT operation upon the beating signal, as shown in Figure 7(b).

\section{Conclusions}

We compared a single-pass Ho:YLF amplifier under freerunning and single-frequency operation. The output energy of $24.2 \mathrm{~mJ}$ with a pulse width of $250 \mathrm{~ns}$ at a PRF of $100 \mathrm{~Hz}$ was obtained. The output spectrum of the singlefrequency pulsed Ho:YLF amplifier was around the P12 $\mathrm{CO}_{2}$ absorption line. The energy stability during $30 \mathrm{~min}$ was improved from $3.8 \%$ to $1 \%$ after the single-frequency pulsed Ho:YLF laser was amplified. The pulse build-up time of the Ho:YLF amplifier under single-frequency operation was $0.37 \mu \mathrm{s}$ shorter than that under free-running operation. Compared with free-running operation, the absence of mode beating of the temporal pulse shape was due to the singlefrequency operation of the Ho:YLF amplifier. The line width of the single-frequency pulsed Ho:YLF amplifier measured by a heterodyne technique was $2.81 \mathrm{MHz}$.

\section{Acknowledgements}

This work was supported by the National Natural Science Foundation of China (No. 51572053).

\section{References}

1. T. Y. Dai, Y. L. Ju, X. M. Duan, Y. J. Shen, B. Q. Yao, and Y. Z. Wang, Appl. Phys. Express 5, 082702 (2012).

2. L. Wang, C. Q. Gao, M. W. Gao, L. Liu, and F. Y. Yue, Appl. Opt. 52, 1272 (2013).

3. J. R. Yu, Opt. Lett. 23, 780 (1998).

4. Q. Wang, C. Q. Gao, Q. X. Na, Y. X. Zhang, Q. Ye, and M. W. Gao, Appl. Phys. Express 10, 042701 (2017).

5. T. Y. Dai, Y. L. Ju, B. Q. Yao, Y. J. Shen, W. Wang, and Y. Z. Wang, Opt. Lett. 37, 1850 (2012).

6. G. J. Koch, J. P. Deyst, and M. E. Storm, Opt. Lett. 18, 1235 (1993).

7. S. W. Henderson, P. J. M. Suni, C. P. Hale, S. M. Hannon, J. R. Magee, D. L. Bruns, and E. H. Yuen, IEEE Trans. Geosci. Remote Sens. 31, 4 (1993).

8. P. A. Budni, C. R. Ibach, S. D. Setzler, E. J. Gustafson, R. T. Castro, and E. P. Chicklis, Opt. Lett. 2, 1016 (2003).

9. Y. X. Zhang, C. Q. Gao, Q. Wang, Q. X. Na, M. W. Gao, M. Zhang, and S. Huang, Appl. Opt. 57, 4222 (2018).

10. A. Dergachev, P. F. Moulton, and T. E. Drake, in Advanced Solid-State Photonics (2005), paper 608.

11. W. Koen, C. Bolling, H. Straus, M. Schellhorn, C. Jacobs, and M. J. D. Esser, Appl. Phys. B 99, 101 (2009).

12. Y. X. Bai, J. R. Yu, M. Petros, P. Petzar, B. Trieu, H. Lee, and U. Singh, in Advanced Solid State Lasers (2009), paper WB22.

13. R. A. Toth, L. R. Brown, C. E. Miller, V. M. Devi, and D. C. Benner, J. Quant. Spectrosc. Radiat. Transfer 109, 906 (2008).

14. L. Joly, F. Gibert, B. Grouiez, A. Grossel, B. Parvitte, G. Durry, and V. Zéninari, J. Quant. Spectrosc. Radiat. Transfer 109, 426 (2008).

15. Y. X. Bai, J. R. Yu, P. Petzar, M. Petros, S. S. Chen, B. Trieu, H. Lee, and U. Singh, in Conference on Lasers and ElectroOptics/International Quantum Electronics Conference (1995), paper CWH5.

16. F. Gibert, D. Edouart, C. Cénac, and F. L. Mounier, Appl. Phys. B 116, 967 (2014).

17. J. Wu, Y. P. Wang, T. Y. Dai, Y. L. Ju, B. Q. Yao, and Y. Z. Wang, Infrared Phys. Technol. 92, 367 (2018).

18. Y. P. Wang, T. Y. Dai, X. Y. Liu, Y. L. Ju, and B. Q. Yao, Opt. Lett. 44, 6049 (2019). 